\title{
Enade: uma análise quanti-qualitativa dos exames nacionais de Odontologia
}

\author{
Suzely Adas Saliba Moimaz"; Marcelo Augusto Amaral**; Cléa Adas Saliba Garbin* \\ * Professora Titular do Departamento de Odontologia Infantil \\ e Social da Faculdade de Odontologia de Araçatuba da \\ Universidade Estadual Paulista. \\ ** Doutorando do Programa de Pós-Graduação em \\ Odontologia Preventiva e Social da Faculdade de \\ Odontologia de Araçatuba da Universidade Estadual \\ Paulista
}

Recebido em 21/10/2016. Aprovado em 23/01/2017.

\begin{abstract}
RESUMO
Objetivou-se analisar as edições do Exame Nacional de Desempenho dos Estudantes (Enade) de Odontologia, em relação ao componente específico, além de verificar os conteúdos abordados na área de Saúde Coletiva. Realizou-se uma pesquisa documental com análise das avaliações de 2004, 2007, 2010 e 2013. Os conteúdos textuais dos enunciados das questões da área de Saúde Coletiva foram processados no software IRAMUTEQ e analisados pelas técnicas lexicográficas de Classificação Hierárquica Descendente e Nuvem de Palavras. A área que apresentou maior número de questões foi Saúde Coletiva (28 questões), o que representou 23,33\% dos conteúdos de todos os exames. As subáreas de administração e políticas públicas e epidemiologia em saúde bucal apresentaram 13 e 10 questões $(10,83 \%$ e $8,33 \%)$, respectivamente. Segundo a análise qualitativa, foram observadas 2.478 ocorrências de palavras, sendo 798 formas distintas, com frequência média de três palavras para cada forma no corpus textual. Destas, foram encontradas 500 palavras equiparadas por meio de Classificações Hierárquicas Descendentes e que resultaram em seis classes diferentes: saúde pública, estratégia saúde da família, levantamento nacional, recursos humanos, SUS e Política Nacional De Saúde Bucal (PNSB). A classe PNSB $(21,4 \%)$ foi a mais prevalente e caracterizada pelas palavras: SB $\left(45,3 \chi^{2}\right)$, Brasil $\left(37,7 \chi^{2}\right)$ e Epidemiológico $\left(37,0 \chi^{2}\right)$. A área de Saúde Coletiva e os conteúdos sobre PNSB, Estratégia Saúde da Família e SUS demostraram ser de grande relevância no exame, o que reforça o direcionamento apresentado nas Diretrizes Curriculares Nacionais para os cursos de Odontologia no Brasil.

Descritores: Avaliação Educacional. Educação Superior. Ensino. Odontologia.
\end{abstract}

\section{INTRODUÇÃO}

A avaliação da educação superior tem destaque dentre as políticas educacionais desde meados da década de 1990, com a criação de avaliações periódicas das instituições e cursos superiores e obrigatória para todos os estudantes concluintes a partir de 1996.

Inicialmente foi regulamentada por meio 
do Exame Nacional de Cursos (ENC), também conhecido como Provão ${ }^{1}$, que foi aplicado anualmente durante oito anos, de 1996 a 2003.

É inconteste que o ENC despertou atenção e interesse da mídia para a questão da qualidade da educação superior brasileira. Trouxe importantes elementos para a reflexão e identificação de distorções dos Projeto Pedagógicos dos Cursos e sua execução, visando à qualidade dos cursos, e consequentemente, o alcance de melhor desempenho neste exame ${ }^{2}$. No entanto, nunca foi unanimidade entre os estudiosos desta temática.

Conforme amplamente documentado na literatura, o ENC nasce no âmbito de globalização e neoliberalismo, em que o ensino superior é caracterizado por massificação e diversificação, por um lado, e maior autonomia institucional, por outro. Neste contexto, o Estado, buscando conter despesas públicas e valorizando a alocação de recursos escassos, inicia uma política de "gerenciamento à distância"3.

Diante da complexidade e importância da cultura avaliativa, a qualidade do ensino no Brasil é enfatizada pela Lei de Diretrizes e Bases da Educação Nacional - Lei no. 9.394 de 20 de dezembro de $1996^{4}$. Posteriormente surge o Sistema Nacional de Avaliação da Educação Superior (SINAES), instituído pela Lei $\mathrm{n}^{\circ}$. 10.861, de 14 de abril de $2004^{5}$.

O Exame Nacional de Desempenho dos Estudantes (Enade) é a parcela do SINAES, em substituição ao ENC, que responde pela avaliação dos estudantes da educação superior na atualidade. Este exame é aplicado trienalmente, em lugar da frequência anual do Provão e se propõe a verificar várias dimensões de competências e habilidades profissionais em um processo avaliativo mais abrangente. Ele é composto por dez questões de formação geral (objetivas e discursivas) e trinta questões de componente específico (objetivas e discursivas).

Uma década depois, surge o Plano
Nacional de Educação (PNE), Lei $\mathrm{n}^{\circ}$ 13.005/2014, como um instrumento de planejamento do Estado democrático de direito que orienta a execução e o aprimoramento de políticas públicas do setor. O PNE 2014-2024 trouxe diversas diretrizes, entre elas a qualidade da educação superior, que visa aperfeiçoar o SINAES, fortalecendo as ações de avaliação, regulação e supervisão, ampliar a cobertura dos processos avaliativos e fomentar a melhoria dos resultados de aprendizagem, de modo que, em cinco anos, pelo menos $60 \%$ dos estudantes apresentem desempenho positivo igual ou superior $60 \%$ no Enade 6 .

$\mathrm{Na}$ presente pesquisa objetivou-se analisar as edições do Enade para os Cursos de Odontologia em relação ao componente específico, além de verificar os conteúdos abordados na área de Saúde Coletiva.

\section{METODOLOGIA}

Realizou-se pesquisa documental de todas edições do Enade para o curso de Odontologia, desde a sua instituição até o ano de 2013. Foram analisadas as edições das avaliações de 2004, 2007, 2010 e 2013, por meio de consulta no portal do Instituto Nacional de Estudos e Pesquisas Educacionais ${ }^{7}$.

Para análise quantitativa e respectiva classificação das questões objetivas das especialidades presentes nos exames, foram utilizadas as áreas de competência elencadas na Resolução 63 do Conselho Federal de Odontologia $(\mathrm{CFO})^{8}$ : a) Cirurgia e Traumatologia Buco-Maxilo-Faciais (artigo 42); b) Dentística (artigo 52); c) Disfunção Temporomandibular e Dor Orofacial (artigo 54); d) Endodontia (artigo 56); e) Estomatologia (artigo 58); f) Radiologia Odontológica e Imaginologia (artigo 60); g) Implantodontia (artigo 62); h) Odontologia Legal (artigo 64); i) Odontogeriatria (artigo 66); j) Odontologia do Trabalho (artigo 
68); k) Odontologia para Pacientes com Necessidades Especiais (artigo 70); 1) Odontopediatria (artigo 72); m) Ortodontia (artigo 74); n) Ortopedia Funcional dos Maxilares (artigo 76); o) Patologia Bucal (artigo 78); p) Periodontia (artigo 80); q) Prótese Buco-MaxiloFacial (artigo 82); r) Prótese Dentária (artigo 84).

As áreas de Patologia Bucal e Estomatologia, por trabalharem conteúdos afins, foram agrupadas em uma única área de análise (Patologia/Semiologia/Estomatologia).

As áreas básicas incluíram os conteúdos teóricos e práticos de base moleculares e celulares dos processos normais e alterados, da estrutura e função dos tecidos, órgãos, sistemas e aparelhos, aplicados às situações decorrentes do processo saúde-doença no desenvolvimento da prática assistencial de Odontologia ${ }^{9}$.

A área de Clínica Integrada referiu-se aos conhecimentos de Materiais Dentários, Oclusão, Dentística, Endodontia, Periodontia, Prótese, Implantodontia, Cirurgia e traumatologia BucoMaxilo-Faciais utilizados em clínica odontológica9 .

O critério para inclusão no grupo de áreas que foram analisadas de forma quanti-qualitativa foi ter apresentado no mínimo três questões ao longo dos quatro exames de desempenho avaliados. Neste sentido, com relação ao componente específico, as questões foram divididas em áreas: Básicas; Odontologia Legal; Saúde Coletiva; Patologia/Semiologia/Estomatologia; Radiologia; Dentística; Periodontia; Endodontia; Cirurgia; Odontopediatria; Ortodontia; Prótese e Clínica Integrada.

Todas as áreas elencadas neste estudo foram quantificadas para posterior apresentação gráfica dos resultados, da mesma forma ocorreu a análise quantitativa das questões de Saúde Coletiva, segundo as subáreas abaixo descritas.

As questões da área de Saúde Coletiva foram reclassificadas quanto ao seu conteúdo nas seguintes subáreas: epidemiologia em saúde bucal, administração e políticas públicas de saúde e gestão administrativo-operacional (incluído organização de serviços, gerenciamento e administração em saúde pública, vigilância sanitária, controle das doenças e educação em saúde pública) também conforme Artigo 86 da Consolidação das Normas para Procedimentos nos Conselhos de Odontologia (Resolução 63) ${ }^{8}$.

Para análise qualitativa, os conteúdos textuais dos enunciados das questões da área de Saúde Coletiva foram processados no software IRAMUTEQ e analisados pelas técnicas lexicográficas de Classificação Hierárquica Descendente (CHD) e Nuvem de Palavras.

O IRAMUTEQ (Interface de $R$ pour lês Analyses Multidimensionnelles de Textes et de Questionnaires) é um software livre que se ancora na linguagem de programação $R$, e que permite processamento e análises estatísticas de textos produzidos e corpus textuais diversos. Foi desenvolvido por Ratinaud ${ }^{10}$ na língua francesa, mas atualmente possui tutoriais completos em outras línguas. Oferece a possibilidade de diferentes formas de análise de dados textuais, desde aquelas bem simples, como a lexicografia básica (como cálculo de frequência de palavras), até análises multivariadas (CHD) ${ }^{11}$.

A CHD é um método proposto por Reinert $^{12}$ que visa obter classes de palavras a partir de corpus textuais, que ao mesmo tempo, apresentam significado/vocabulário semelhante entre si, e diferentes nos segmentos de textos das demais classes. Organiza a análise qualitativa dos textos em um dendograma, que apresenta graficamente as classes e suas possíveis relações. De acordo com as classes e frequência/testes tipo $\chi^{2}$ das palavras fornecidas pelo IRAMUTEQ, o pesquisador nomeia as mesmas de acordo com sua semântica na área pesquisada.

O software, para realizar análises lexicais 
clássicas, identifica e reformata as unidades de texto, que se transformam de Unidades de Contexto Iniciais (UCI) em Unidades de Contexto Elementar (UCE).

A Nuvem de Palavras é uma análise mais simples, que trabalha com a representação gráfica em função da frequência das palavras e permite facilmente sua identificação visual por meio de uma figura gerada pelo software IRAMUTEQ.

Após o processamento do conteúdo textual, construiu-se o modelo analítico composto por categorias, que corresponderam às classes de palavras geradas pelo software IRAMUTEQ e CHD. As categorias podem ser estabelecidas antes do trabalho de campo, na fase exploratória da pesquisa, ou a partir da coleta de dados, e nesta pesquisa optou-se pela utilização destas categorias analíticas pós-coleta por serem mais específicas, concretas e por critério léxico ${ }^{13}$.

A análise interpretativa do corpus se deu pelo uso da Análise de Conteúdo, por poder ser esta quantitativa e qualitativa. Na abordagem quantitativa se traça uma frequência das características (palavras) que se repetem no conteúdo do texto. Na qualitativa, se considera o conjunto de características em um determinado fragmento do conteúdo ${ }^{14}$.
Por se tratar de pesquisa com dados secundários públicos, dispensa-se a avaliação por Comitê de Ética em Pesquisa.

\section{RESULTADOS E DISCUSSÃO}

A análise das avaliações aplicadas no Enade para os cursos de Odontologia no período 2004/2013 indicou convergência das características empíricas em torno de seis temas/ categorias: a) saúde pública; b); estratégia saúde da família; c) levantamento nacional; d) recursos humanos; e) SUS; e f) política nacional de saúde bucal.

Nesta análise observou-se aumento significativo do número de questões de Saúde Coletiva ao longo dos anos. No exame de 2004 houve 26 questões objetivas e quatro questões discursivas para o componente específico. A área de Saúde Coletiva apresentou cinco questões $(16,66 \%)$, sendo quatro objetivas e uma discursiva. Este número poderia ser considerado ainda maior ( 7 ou 23,33\%), se contabilizadas as questões de conteúdos afins nas áreas de Odontologia Legal (questão 13) e Odontopediatria (questão 24) para esta edição, e que correspondem a temas de interface da Saúde Coletiva (gráfico 1).

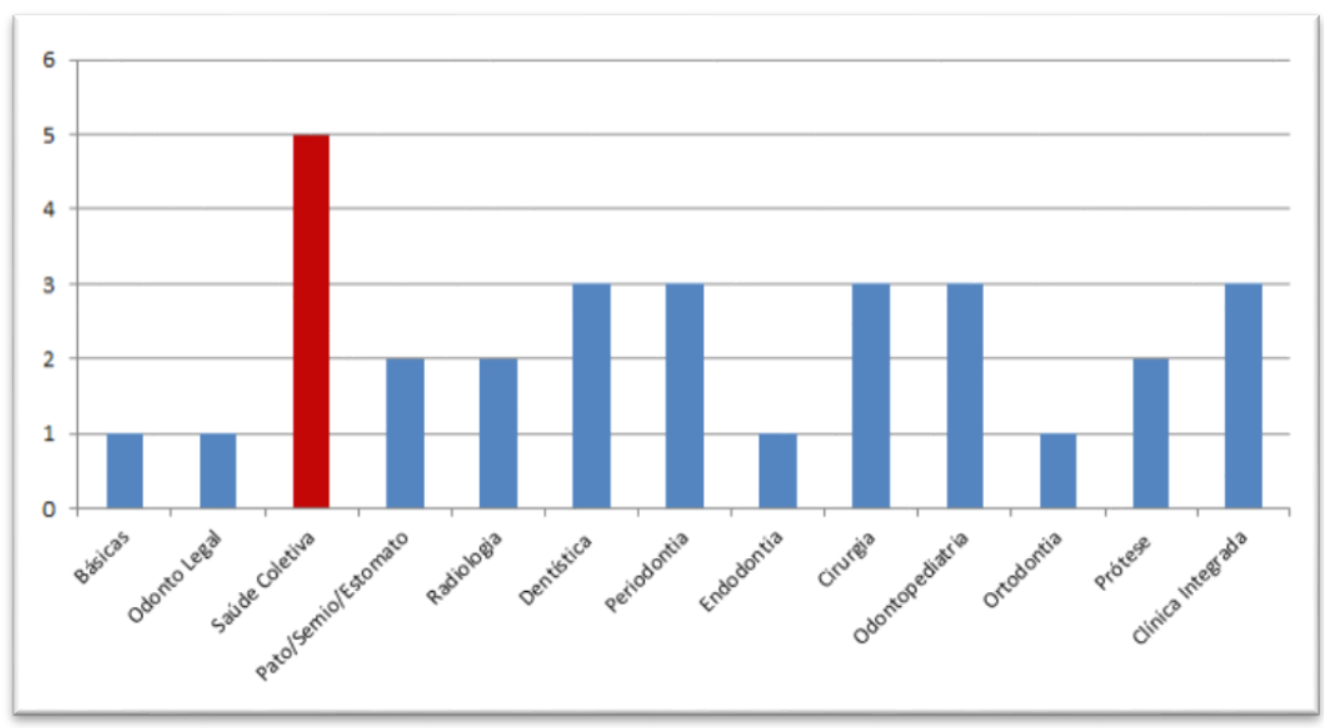


Gráfico 1. Distribuição de questões do componente específico do Enade 2004 (n=30).

No Enade de 2007 o conteúdo de Saúde aplicadas 26 questões objetivas e quatro questões de Coletiva apresentou sete questões $(23,33 \%)$, sendo cinco objetivas e duas discursivas. O conteúdo de Odontologia Legal apresentou quatro questões objetivas $(13,33 \%)$. Para o referido ano, foram cunho discursivo. O número de questões de Saúde Coletiva poderia representar $36,66 \%$ do exame (11) se considerada a interface com a área de Odontologia Legal neste exame (gráfico 2).

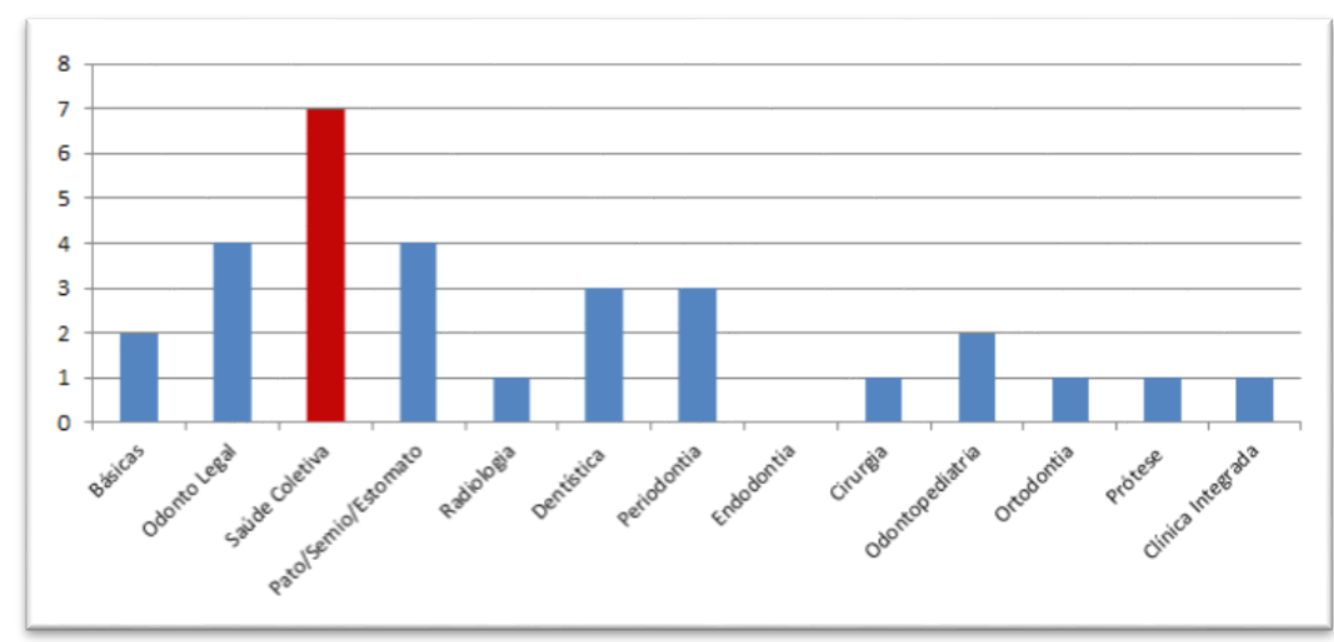

Gráfico 2. Distribuição de questões do componente específico do Enade 2007 (n=30).

Diferente da distribuição de questões objetivas dos exames de 2004 e 2007, no Enade de 2010 houve 27 questões objetivas e três discursivas. Destas, oito questões $(26,66 \%)$ contemplaram os conteúdos de Saúde Coletiva e as objetivas (7) foram as mais prevalentes neste ano (gráfico 3). A área de Odontologia Legal apresentou duas questões, e se considerado alguns conteúdos afins para este exame, caso das questões de Odontopediatria (29) e básicas (33) poder-se-ia ter $40 \%$ (12) de itens envolvendo temas da Saúde Coletiva e áreas conexas.

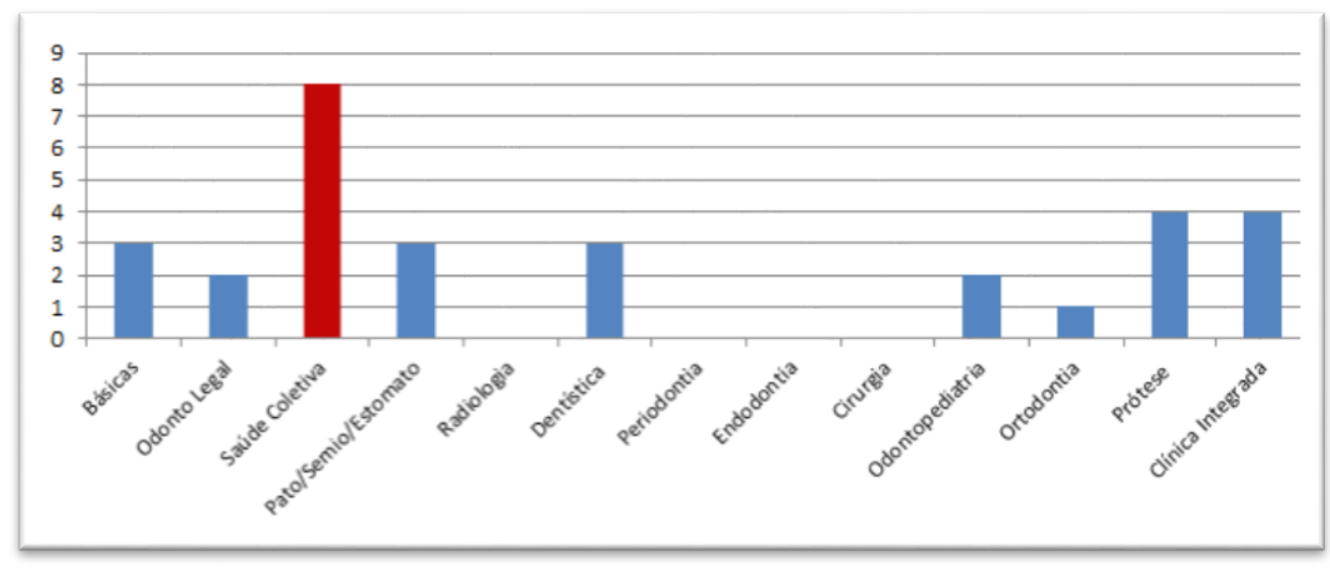

Gráfico 3. Distribuição de questões do componente específico do Enade 2010 (n=30). 
A Saúde Coletiva tem um papel de grande importância na formação do futuro cirurgiãodentista com o perfil exigido pelas Diretrizes Curriculares Nacionais (DCN) do curso de Odontologia e pela sociedade, ou seja, com formação generalista, socialmente sensível e principalmente sempre disposto a aprender ${ }^{15}$.

De acordo com a Resolução 63 do CFO, a Saúde Coletiva é a especialidade que tem como objetivo o estudo dos fenômenos que interferem na Saúde Coletiva, por meio de análise, organização, planejamento, execução e avaliação de sistemas de saúde, dirigidos a grupos populacionais, com ênfase na promoção de saúde ${ }^{8}$.

O exame de 2013, apresentou um grande número de questões referentes a área de Saúde Coletiva, com número similar ao exame anterior. Sete questões objetivas e uma discursiva (26,66\%) contemplaram conteúdos da Saúde Coletiva e que se enquadravam no Artigo 86 da Resolução $63^{8}$ (gráfico 4). Caso considerado, as interfaces com a Odontologia do Trabalho e áreas básicas (questões 13 e 27) e Odontopediatria (questão 30), haveria 36,6\% (11 itens) de temáticas de Saúde Coletiva neste Enade.

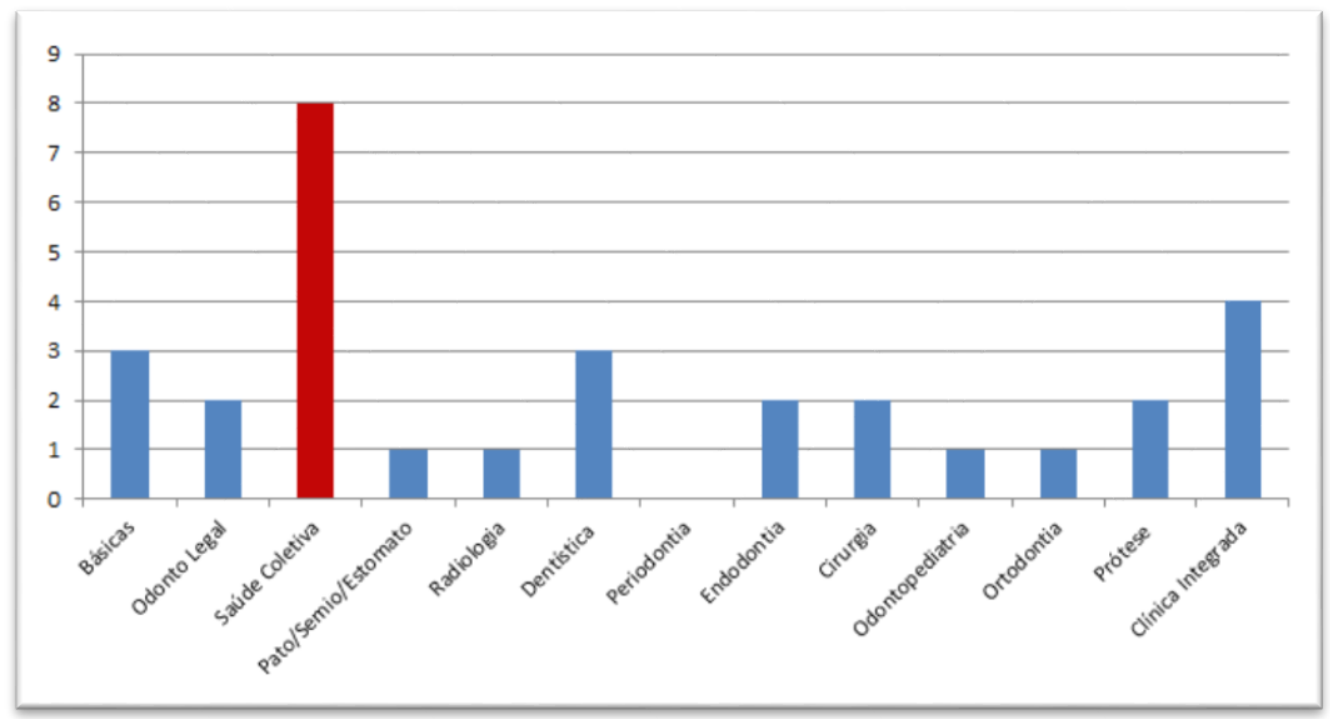

Gráfico 4. Distribuição de questões do componente específico do Enade 2013 (n=30).

Ao analisar as edições do Enade verificouse relativa interface de conteúdos com áreas afins ao longo de todos os anos em algumas questões, principalmente envolvendo as especialidades de Odontologia Legal e Odontopediatria, e em alguns casos com as áreas básicas e Odontologia do Trabalho. Esta interface referiu-se a questões envolvendo conteúdos que podem ser estudados e classificados como sendo de Saúde Coletiva, ou serem considerados competências transversais, e presentes em disciplinas de estágios ou clínicas e nos últimos anos do curso.

$\mathrm{Na}$ formação acadêmica, os estudantes estão sujeitos às competências técnicas e transversais, sendo as técnicas mais observadas nos anos iniciais do curso e as competências transversais a partir do início das clínicas integradas e semestres finais da formação (período dos estágios). Para os concluintes, as competências transversais foram as mais significativas para sua formação. As competências de hoje são provisórias e sujeitas a mudan- 
ças. Os currículos devem possibilitar essas mudanças, reconstruindo-se continuamente ${ }^{16}$.

Outro ponto a ser discutido é a interface encontrada em apenas algumas áreas ou especialidades de competências transversais, sendo que, a maior parte das áreas avaliadas nesta pesquisa $(69,23 \%)$ aparecem desvinculadas a Saúde Coletiva, e o que desatende as DCN, que estabelecem que todo curso de graduação em Odontologia deverá, por meio do projeto pedagógico, buscar a formação integral e adequada do estudante através de uma articulação entre as áreas de competências e o ensino, a pesquisa e a extensão/assistência ${ }^{9}$.

Em estudo realizado por pesquisadores do Departamento de Odontologia Preventiva e Social da FOA/UNESP considerou-se também essenciais, na composição da carga horária da Saúde Coletiva, os estágios extramuros e a extensão universitária ${ }^{15}$.

A área que apresentou maior número de questões foi Saúde Coletiva (28 questões), o que representou $23,33 \%$ dos conteúdos de todos os exames. Se considerado os conteúdos afins, as temáticas de Saúde Coletiva poderiam significar $34,16 \%$ de todos os Enade de Odontologia. Os conteúdos essenciais para o Curso de Graduação em Odontologia devem estar relacionados com todo o processo saúde-doença do cidadão, da família e da comunidade, integrado à realidade epidemiológica e profissional ${ }^{9}$.

Respectivamente, as subáreas de administração e políticas públicas de saúde e epidemiologia em saúde bucal apresentaram 13 e 10 questões $(10,83 \%$ e $8,33 \%)$ dos conteúdos de Saúde Coletiva apresentados nas edições avaliadas (gráfico 5). A formação do cirurgiãodentista deverá contemplar o sistema de saúde vigente no país, a atenção integral da saúde num sistema regionalizado e hierarquizado de referência e contrarreferência e o trabalho em equipe $^{9}$.

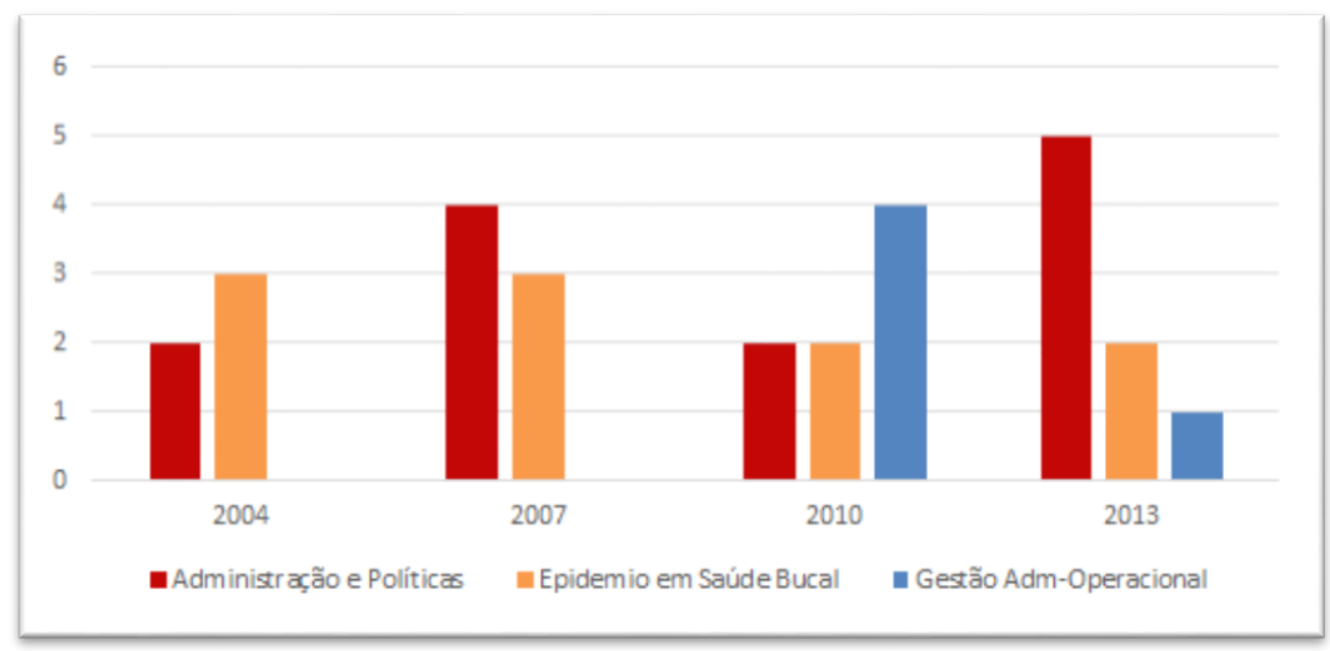

Gráfico 5. Distribuição das subáreas de Saúde Coletiva nos exames de 2004, 2007, 2010 e 2013 (n=28).

Ao se analisar tais resultados do Enade, não se pode discutir a relevância da área de Saúde Coletiva para o Enade. No entanto, não se acredita ser isto suficiente para consolidação das DCN no território nacional.

Considerando as três dimensões necessárias para a formação de um profissional de acordo com as DCN (ensino, pesquisa e extensão), o Enade 
avalia somente a primeira delas.

Estudo de Moimaz et al. ${ }^{17}$, comprova a eficiência da extensão universitária como agente fomentador das DCN. O programa de extensão revelou ser um importante agente para o processo individual e coletivo de formação acadêmica, que não se limita ao tradicional, uma vez que, contribui para a formação de profissional da saúde mais humanista, generalista e preparado para atuar frente à situação de saúde de nosso país, como preconizam as DCN.

As atividades de extensão universitária são espaços para reflexões acerca de possíveis transformações na condução da promoção de saúde e no controle de agravos e à população que, em contato com a realidade dos serviços públicos, pode repensar a melhor forma de agir coletivamente nos locais de atuação ${ }^{18}$.

Segundo a análise qualitativa, foram observadas 2.478 ocorrências de palavras, sendo 798 formas distintas, com frequência média de três palavras para cada forma no corpus textual. Destas, foram encontradas 500 unidades de contexto elementares, ou seja, $62,65 \%$ do total de palavras foram equiparadas por meio de CHD de segmentos de texto de tamanhos diferentes, indicando o grau de semelhança no vocabulário das seis classes resultantes: saúde pública, estratégia saúde da família, levantamento nacional, recursos humanos, SUS e política nacional de saúde bucal (PNSB). A classe PNSB $(21,4 \%)$ foi a mais prevalente, e caracterizada pelas palavras: SB $\left(45,3 \chi^{2}\right)$, Brasil $\left(37,7 \chi^{2}\right)$ e Epidemiológico $\left(37,0 \chi^{2}\right)$ (figura 1). Esta análise apresentada compõe a lexicografia básica (frequência de palavras), e análise multivariada (CHD) a partir do corpus textual dos enunciados das questões da área de Saúde Coletiva.

Alguns dos conteúdos abordados nos exames nacionais são vivenciados na prática dos estágios supervisionados curriculares preconizado pelas DCN para o curso de Odontologia, no entanto, outros deixam de ser contemplados e a avaliação trienal do Enade avalia somente as competências teóricas dos estudantes concluintes.

O estágio curricular supervisionado é um componente obrigatório para os cursos de graduação em Odontologia e sua definição deve estar respaldada, descrita com o detalhamento necessário ao acompanhamento como atividade de ensino e supervisionado em todas as etapas de desenvolvimento. Deve ser distinto de outras atividades práticas necessárias à formação do cirurgião dentista, além de apresentar diretrizes atualizadas à luz da legislação vigente e melhores práticas educacionais ao atendimento do perfil proposto pelas $\mathrm{DCN}^{19}$.

Ainda segundo Moimaz et al. ${ }^{20}$, os estágios curriculares supervisionados são contemplados na maioria dos cursos de Odontologia, com cargas horárias e nomenclaturas diversificadas, entretanto, há diferentes formas de compreensão, pois suas características não estão totalmente de acordo com as DCN e muitas disciplinas e conteúdos de formação são ainda designados com atividades de estágio.

Seria extremamente importante e útil avaliar a percepção dos alunos sobre o estágio supervisionado, bem como um olhar mais crítico das instituições de ensino superior sobre o que traria como consequência o estágio e sua prática de ensino na formação dos profissionais. E seriam necessários estudos de avaliação dos estágios supervisionados após cada edição do Enade, e que atualmente inexistem em cenário nacional e regional. O Enade é uma importante ferramenta de avaliação da educação superior na área de Odontologia, no entanto, este não é capaz de impulsionar mudanças na realidade de estágio curricular mencionada acima e que descumprem as DCN.

$\mathrm{Na}$ figura 1, pode-se visualizar um diagrama que demonstra as classes/categorias advindas 
das partições do conteúdo que indicaram o grau de semelhança no vocabulário dos enunciados das questões de Saúde Coletiva dos Enades avaliados e seus principais conteúdos resultantes da análise interpretativa.

Para a construção do dendograma apresentado na figura 1 e subsequente análise foram consideradas as palavras com frequência igual ou maior que a média $(2,33)$. Cada classe é descrita pelas palavras mais significativas e pelas suas respectivas associações com a classe (Teste do Qui-quadrado).

O software IRAMUTEQ pode trazer importantes contribuições aos estudos que envolvam corpus textuais e torna possível integrar métodos quantitativos e qualitativos de análise, trazendo maior objetividade e avanços às interpretações ${ }^{21}$.

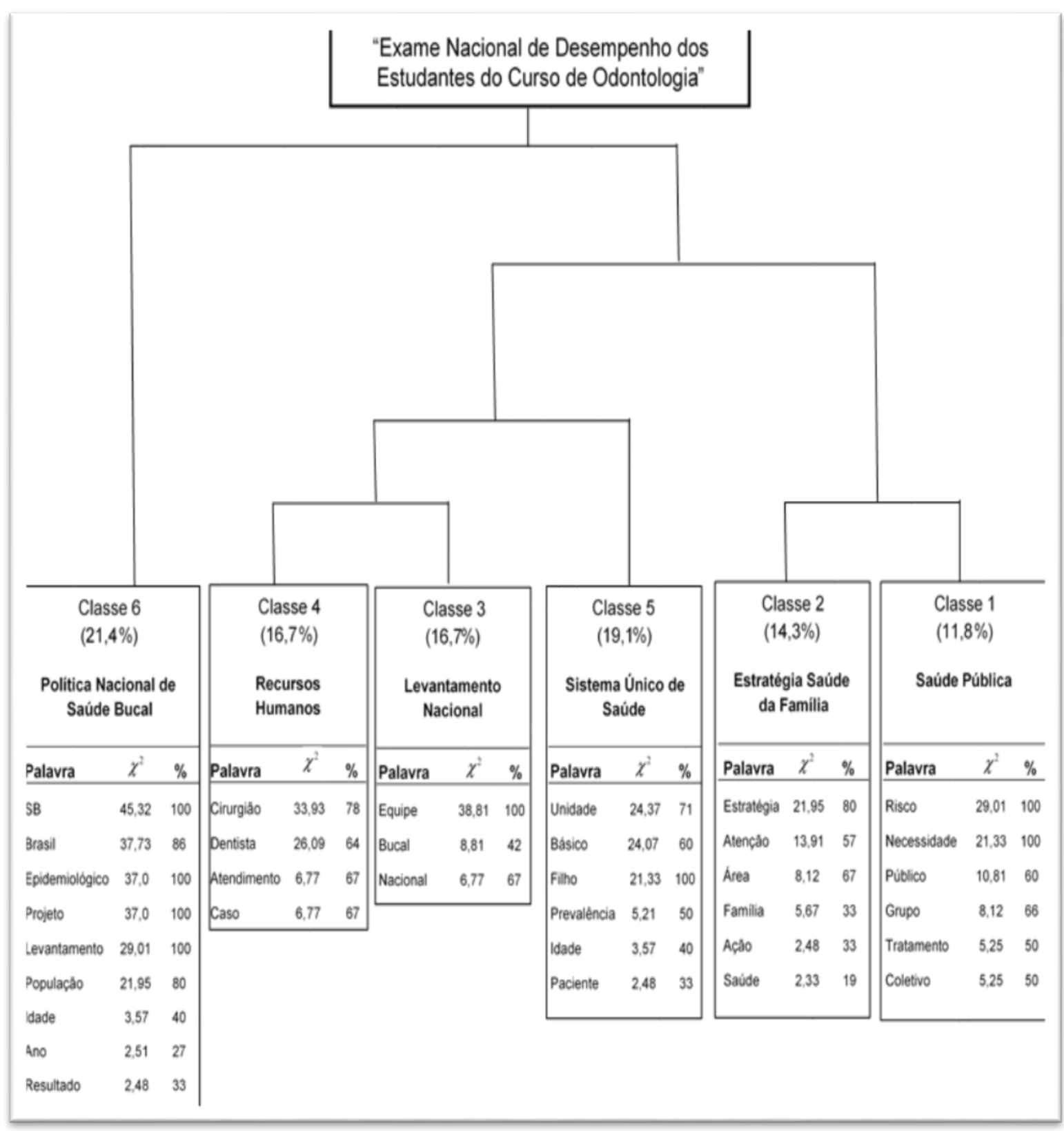

Figura 1. Dendograma da CHD com as partições e conteúdo do corpus da pesquisa. 
No que diz respeito ao método da "Nuvem de Palavras", ocorre também o agrupamento e organização gráfica das palavras em função da sua frequência, possibilitando rápida identificação das palavras-chave do corpus textual e análise lexical simples $^{221}$. Nesse estudo, verificou-se que as palavras que obtiveram frequência relativa foram: "saúde, família, dentista, criança e dentário, que constaram 32, 12, 11, 9 e 8 vezes, respectivamente, na transcrição do corpus textual" (figura 2).

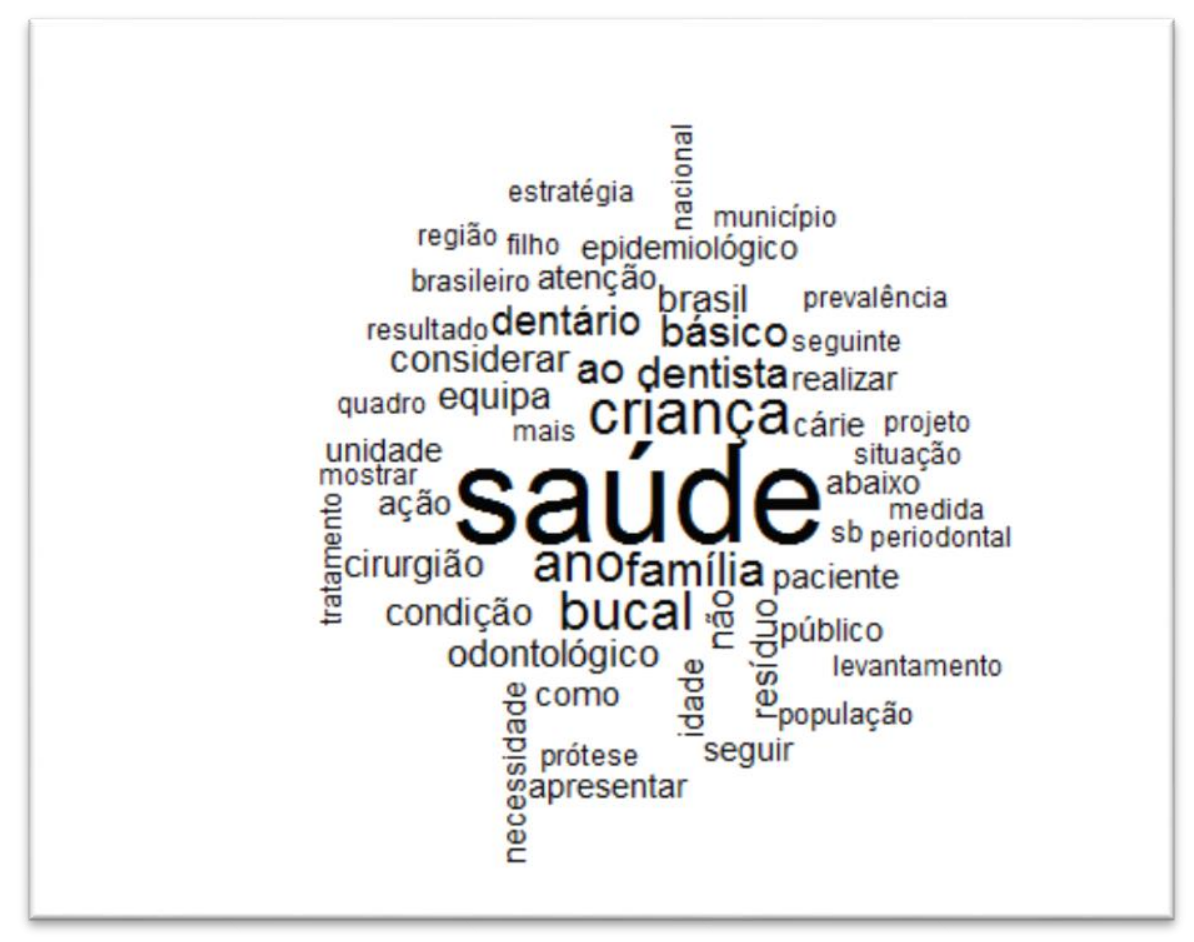

Figura 2. Nuvem de Palavras das questões de Saúde Coletiva do Enade.

\section{CONCLUSÕES}

A área de Saúde Coletiva e a subárea de administração e políticas públicas de saúde prevaleceram sobre as demais áreas em todas as edições do Enade, o que reforça o direcionamento apresentado nas DCN para os cursos de Odontologia no Brasil.

Os conteúdos sobre Política Nacional de Saúde Bucal, Estratégia Saúde da Família e SUS, pela análise qualitativa, demonstraram ser de grande relevância nas avaliações dos exames nacionais de Odontologia.

\section{ABSTRACT \\ Enade: a quantitative and qualitative analysis}

\section{of national exams in Dental courses}

This study aimed to analyze the issues of the National Student Performance Exam (Enade) in Dentistry courses in relation to the specific component, and check the contents addressed in collective health. The research was conducted with analysis of ratings of 2004, 2007, 2010 and 2013 Enade. The textual content of the statements of the issues of public health area was processed in IRAMUTEQ software and analyzed by lexicographical techniques such as Descending Hierarchical Classification and Words Cloud. The area with the highest number of issues was public health (28) which represented $23.33 \%$ of the contents of all examinations. Subareas administration and public policy and epidemiology in oral health 
presented 13 and 10 questions (10.83\% and $8.33 \%$ ) respectively. According to the qualitative analysis, 2.478 occurrences of words were found, and 798 different forms, with an average frequency of three words for each form in the textual corpus. Of these, 500 were found words matched by Ratings Hierarchical Descendants and that resulted in six different classes: public health, family health strategy, national survey, human resources, SUS and national oral health policy (PNSB). The PNSB class $(21.4 \%)$ was the most prevalent, and characterized by the words: SB (45.3 $\chi 2)$, Brazil (37.7 $\chi 2)$ and Epidemiology $(37.0 \chi 2)$. The Public Health, and the contents of the National Oral Health Policy, Health Strategy and SUS, demonstrated to be of great relevance in the examination, which reinforces the direction presented in the National Curriculum Guidelines for Dentistry courses in Brazil.

Descriptors: Educational Measurement. Education, Higher. Teaching. Dentistry.

\section{REFERÊNCIAS}

1. Brasil. Lei $n^{\circ} .9 .131$, de 24 de novembro de 1995. Altera dispositivos da Lei $n^{\circ} .4 .024$, de 20 de dezembro de 1961 e dá outras providências. Diário Oficial da União 1995; nov 25.

2. Paiva GS. Avaliação do desempenho dos estudantes da educação superior: a questão da equidade e obrigatoriedade no Provão e Enade. Ensaio: Aval Pol Públ Educ. 2008; 16(58):31-46.

3. Verhine RE, Dantas LMV, Soares JF. Do Provão ao ENADE: uma análise comparativa dos exames nacionais utilizados no Ensino Superior Brasileiro. Ensaio: Aval Pol Públ Educ. 2006;14(52):291-310.

4. Brasil. Lei $n^{\circ}$. 9.394, de 20 de dezembro de 1996. Estabelece as Diretrizes e Bases da Educação Nacional. Diário Oficial da União 1996; dez 23.

5. Brasil. Lei $\mathrm{n}^{\circ} .10 .861$, de 14 de abril de 2004. Institui o Plano Nacional de Avalia- ção da Educação Superior e dá outras providências. Diário Oficial da União 2004; abr 15.

6. Brasil. Lei ${ }^{\circ} .13 .005$, de 25 de junho de 2014. Institui o Plano Nacional de Educação (PNE) e dá outras providências. Diário Oficial da União 2014; jun 26.

7. INEP. Instituto Nacional de Estudos e Pesquisas Educacionais Anísio Teixeira. Exame Nacional de Desempenho dos Estudantes - ENADE. (Acesso em: 20 set. 2016). Disponível em: http://portal.inep.gov.br/ enade

8. Conselho Federal de Odontologia. Resolução 63, de 30 de junho de 2005. Institui a Consolidação das Normas para Procedimentos nos Conselhos de Odontologia.

9. Brasil. Conselho Nacional de Educação. Câmara de Educação Superior. Resolução CNE/CES 3, de 19 de fevereiro de 2002. Institui Diretrizes Curriculares Nacionais do Curso de Graduação em Odontologia. Diário Oficial da União 2002; mar 4.

10. Ratinaud P. IRAMUTEQ: Interface de R pour lês analyses multidimensionnelles de textes et de questionnaires (Computer Software). 2009. (Acesso em: 15 jun. 2016). Disponível em: http:www.iramuteq. org.

11. Lebart L, Salem A. Statistique textuelle. Paris: DUNOP; 1994.

12. Reinert M. Alceste une méthodologie d'analyse des donnés textuelles et une application: Aurelia de Gerard de Nerval. Bull Methodol Sociol. 1990;(26):24-54.

13. Minayo MCS. Pesquisa Social: teoria, método e criatividade. 29a ed. Petrópolis: Editora Vozes; 2010.

14. Bardin L. Análise de Conteúdo. São Paulo: Edições 70; 2011.

15. Rodrigues RPCB, Saliba NA, Moimaz

SAS. Saúde Coletiva nas estruturas 
curriculares dos cursos de Odontologia no Brasil. Rev ABENO. 2006;6(1):81-7.

16. Toassi RFC, Souza JM, Bitencourt F. Currículos integrados e as competências construídas por estudantes de odontologia da Universidade Federal do Rio Grande do Sul. Rev Iberoam Educ. 2016;67(1):43-64.

17. Moimaz SAS, Bordin D, Gomes AMP, Fadel CB, Garbin CAS, Saliba NA.

Extensão universitária da ótica de acadêmicos: o agente fomentador das Diretrizes Curriculares Nacionais. Rev ABENO. 2015;15(4):45-54.

18. Moura LFAD, Bordin D, Piauilino RJB, Araújo IF, Moura MS, Lima CCB, Evangelista LM, Lima MDM. Impacto de um projeto de extensão universitária na formação profissional de egressos de uma universidade pública. Rev Odontol UNESP. 2012;41(6):348-52.

19. Scavuzzi AIF, Gouveia CVD, Carcereri DL, Veeck EB, Ranali J, Costa LJ, Morita MC, Araújo MH. Revisão das Diretrizes da ABENO para a definição do estágio supervisionado curricular nos cursos de Odontologia. Rev ABENO. 2015;15(3):109-13.
20. Moimaz SAS, Wakayama B, Garbin AJI, Garbin CAS, Saliba NA. Análise situacional do estágio curricular supervisionado nos cursos de graduação em Odontologia no Brasil: uma questão de interpretação. Rev ABENO. 2016;16(4):19-28.

21. Camargo BV, Justo AM. IRAMUTEQ: um software gratuito para análise de dados textuais. Temas psicol. 2013;21(2):513-8.

22. Moura LKB, Marcaccini AM, Matos FTC, Sousa AFL, Nascimento GC, Moura MEB. Revisão Integrativa sobre o câncer bucal. R Pesq Cuid Fundam. 2014;6(5):164-75.

Correspodência para:

Profa. Dra. Suzely Adas Saliba Moimaz

e-mail: sasaliba@foa.unesp.br

Programa de Pós-Graduação em Odontologia

Preventiva e Social

Rua José Bonifácio, 1193

16015-050 - Vila Mendonça, Araçatuca/SP 